\title{
Construction and Validation of Academic Stress Scale for University Students
}

\author{
Saima Noreen ${ }^{*}$ \\ Saba Ghayas** \\ Shaista Khalid*** \\ Shumaila Mazhar Awan ****
}

\begin{abstract}
The present study aimed to construct and validate an instrument to measure the academic stress among university students of Pakistan. Item construction of this instrument was based on literature review, interviews from university students and expert's opinion. After pilot study exploratory factor analysis was performed on a sample of 477 student (226 men and 251 women), recruited from different departments of University of Sargodha, Pakistan. 26 items were retained after exploratory factor analysis with three well defined factors (1. Personal, Parental and Teachers' attitude, 2. Perception of workload and examinations, 3. Concerns about education system and management) Range of Alpha coefficients for scale and its subscales was .72 to .87. Results of Confirmatory factor analysis performed on an independent sample revealed excellent model fit to present data. Three factor structure of Academic Stress Scale was confirmed by Confirmatory Factor Analysis. Convergent validity of Academic Stress Scale was proved by finding its positive correlation with UCLA Loneliness Scale, Depression Scale and Brief Fear of Negative Evaluation Scale. Excellent reliability and validity evidences proved this scale as a promising measure of academic stress.
\end{abstract}

Keywords: academic stress, construction, factor analysis, psychometric properties, validation

\footnotetext{
Department of Psychology, University of Sargodha, Pakistan. Email: saimakhan@gmail.com

** Assistant Professor, Department of Psychology, University of Sargodha, Pakistan. Email: saba.ghayas3@gmail.com

*** Department of Psychology, University of Sargodha, Pakistan. Email: Shaista.khalid@uos.edu.pk

**** Department of Psychology, University of Sargodha, Pakistan. Email: shumaila@uos.edu.pk
} 


\section{Introduction}

Stress in academic life has become a vital issue to be researched. Though extensive research have been carried out on stress and its social, psychological, environmental and health related consequences still this area requires more attention (Rees \& Redfern, 2000; Ellison, 2004; Agolla, 2009).

Influence of academic stress can be positive as well as negative (Smith, 2000; Tweedet al., 2004; Stevenson \& Harper, 2006). Its positive aspect can work as a motivator to improve the life quality of students whereas the negative aspect of stress becomes destructive and yields a negative reaction in the life of students (Blonna, 2005). There is disagreement in the views of researchers about the positive or negative influence of academic stress. For instance, according to Kaplan and Sadock (2000) optimal level of stress plays an important role in enhancing the learning capacity of students. A significant positive relationship was examined between emotional stress and students' school performance (Gelow et al, 2009). This optimal stress level is considered necessary for good performance. A negative correlation between academic achievement and stress was found in a study conducted by Malik and Balda (2006). The increased stress level was related with physical health problems that caused psychological distress among Thai students (Klainin-Yobas etal., 2014). Headaches, chest problems, stomach issues and elevated blood pressure was found to be the characteristics of students with a higher level of stress (Farias et al., 2011). There are also many psychological problems faced by stressed students including impaired self-concept, destructive behavior, mood disturbances, anxiety and depression that decline their performance and negatively affect their health (Cooley, Toray, Valdez, \& Tee, 2007). It is assumed that academic stress is cause of pathological symptoms among university students (Ongori, 2007).

Work settings are different in academic institutions as compared to non-academic settings (Chang \& Lu, 2007). Students contribute in development of nation's economy by acquiring necessary knowledge and skills, but academic environment may hinder their success and poses many serious medical problems (Dyck \& Roithmayr, 2001). Perception of environment is different for everyone due to variation in personality characteristics and backgrounds. In a single semester students have to face different stressors like grade competition, presentations, assignments and preparation of exams in short time (Abouserie, 1994). Excessive stress causes physical and psychological impairments in students. Different kinds of coping strategies are used by students to overcome their level of stress. Social support, time management and extracurricular activities help them out to manage their burdened routines (Murphy \& Archer, 1996). 


\section{Literature Review}

According to Fairbrother and Warn (2003) there are many factors causing stress among students like excessive study burden, poor interpersonal relationships, assignments, exams in semester system and competition with class fellows. Factors related to curriculum (Gajalakshmiet al., 2012), Language (Yeh \& Inose , 2003), procrastination (Novoteny, 2010), absence in class (Iyamu \& Obiunu, 2006), conflicts between teacher student relations (Argon, 2009), relationship between fear and learning (Jackson, 2010), Unrealistic expectations (Reynolds et al, 2006) are major sources of stress for students.

Erkutlu and Chafra (2006) indicated that there are some institutional level stressors that cause stress in students such as semester system, overcrowded classrooms, non-availability of teachers, exams and allocated time for them. A study revealed that semester system, overcrowded classrooms, lack of equipment and inadequate resources may be sources of stress for students (Awino \& Agolla, 2008).

Ramli, Alavi, Mehrinezhad, and Ahmadi (2018) conducted a study to find the relationship between academic stress and self-regulation among university students of Klang Valley, Malaysia with mediating role of mindfulness. A significant negative relation was found between academic stress and self-regulation of students. Moreover, it was demonstrated that the students' ability to utilize the functional skills was restricted due to higher level of perceived stress. Another finding indicated negative relationship between mindfulness and academic stress among undergraduate university students in Malaysia.

Reddy, Menon, and Thattil (2018) administered a study to measure the level of academic stress and locate its sources among university students. Study results indicated that academic stress effects the students' mental health as well as their well-being. Stream wise differences were also highlighted in stress experiences. Five big sources of academic stress including fear of failure, personal inadequacy, interpersonal difficulty with teachers, inadequate study facilities and teacher pupil relationships were analyzed. Moreover, life skills, yoga, meditation, mindfulness and biofeedback were found to be effective techniques in reducing stress.

Chacón-Cuberos, Zurita-Ortega, Olmedo-Moreno and Castro-Sánchez (2019) found the relationship between academic stress, diet and physical activity among university students. Associations were traced among gender, academic stress and various health habits. Women showed higher score in communication of own ideas and academic obligations. It was also observed that students facing obesity were higher scorer for academic stress. Those students who followed better quality diet showed lower level of academic 
stress. Two interesting points regarding diet habits were highlighted that level of stress can be reduced by taking balanced diet. Secondly higher level of stress leads towards intake of healthy diet.

Worku, Dirriba, Berhanu, and Fetensa (2020) conducted a research to indicate the relationship between depression, perceived stress, and associated factors among undergraduate university students. Depression and stress were studied as common health issues among students of health sciences that required early recognition and proper intervention. Higher level of perceived stress and lower level of depression was identified among health science students. Pressure to maintain good grade, age, high parental expectations, financial problems and inadequate dormitory safety were different factors associated with stress.

Kalaithasan, Tye, Fatimatuzzahra, Aziz and Tangiisuran (2020) conducted a study concerning with prevalence, factors associated with stress and coping strategies used by university students in a public university in Malaysia. Stress prevalence was found to be relatively higher especially among students of first and third year. Lecture teaching approaches, financial problems, family and peer problems, difficulty in time management, feeling lonely, lack of leisure, unhealthy eating patterns and lack of physical exercise were associated with stress of students. Emotional eating, yoga and meditation, effective time management and balance between regular exercise and academics were studied as common coping strategies to relieve this stress.

Students travelling toward other countries to join universities and different educational courses are exposed to complex challenges specially when there are striking differences between home and host country cultures. This variation of culture affects performance, physical health and psychological well-being of students, their performance and ability to adjust with challenges (Ward, Bochner \& Furnham, 2001). They go there only for study purpose rather than permanent settlement and experience "cultural shock" described by Oberg (1960) that results from loss of symbols associated with everyday life and all familiar signs. There are different factors that hinder to adjust in host culture including age, gender, language proficiency, difference in origin of home and host culture, selfesteem and prior cultural experiences. Moreover, provided information and support, length of stay, academic and professional performance, language proficiency interaction with host nationals and health are important issues for adjustment (Ward \& Rana-Dueba, 1999). A number of emotional stressors including intimacy, autonomy and belief system are experienced by international students. They are also captured by international status difficulties like being away from loved once, intense pressure to excel in academics and discrimination (Mori, 2000). 
According to Furnham (2004) some students are young adults in process of identity development for psychological and financial independence.

Academic stressors are different in individualistic and collectivistic cultures. Stress perception, coping strategies and response towards stress is also different with this regard. In Pakistan, students join university after intermediate level. They have to face a very challenging environment. Assignments, presentations, quiz, practical on daily basis, exams during semester are major academic stressors for our students (Fairbrother \&Warn, 2003). According to Shaikh, Kahloon, Kazmi and Khan (2004) academic stress is experienced by $90 \%$ of students during their course at a single time or other. Irrelevant field selection, language difficulty and political interference are some other sources of stress for Pakistani students (Ahmed et al, 2017). As educational, cultural, and familial patterns do vary from culture to culture and these cultural differences influence the experiences of academic stress differently. Consequently, academic stress should be operationalized in the indigenous context. The nature of academic stress highlights the significance of development of a particular scale for Pakistani students.

For international students learning is more difficult process as they have to face language problems and different cultural values with their academic preparation (Mori, 2000). Common academic stressors are shared by American and international students including financial burdens, family related issues, competition, requirement for scholarships to avoid the stigma of seeking psychological help some students develop somaticized feelings. Some international students become stressed due to their prolonged absence from family members and home country. Intimacy, autonomy and belief system are some emotional stressors faced by them (Mori, 2000).

There are different instruments to measure the academic stress of students from all over the world. However, these instruments are not completely applicable in Pakistani culture due to variations in cultural, social, academic, political and religious backgrounds. Previous researchers tried to explore the area of academic stress by using general stress scale or scale developed for other cultures for instance Perceived Stress Scale-10 (Cohen et al, 1983), institutional stress by Bisht (1998), The College Student Stress Scale (Feldt, 2008), The University Stress Scale (Stallman, 2008), Students Stress Rating Scale (Balamurugan \& Kumaran, 2008), Freshman Stress Questionnaire (Boujut \& BruchonSchweitzer (2009)), Academic Educational Stress Scale by Sun, Dune, Hou and Xu (2011), Perception of Academic Stress Scale by Bedewy and Gabriel (2013). Examination Stress Scale for Adolescent students (Sung $\&$ Chao, 2015), and The University Stress Scale (Stallman et al, 2016).

Translated versions of these scales are also not completely suitable to measure the stress level of Pakistani students because problems 
experienced by Pakistani University students are not similar to the students of other countries. Pakistani students are experiencing different types of parental attitudes, teachers' attitude, demands of society, etc that might not influence the students living in other cultures. So, it is not appropriate to use these versions for our students as they are at different levels of abilities, individual differences and internal and external factors influencing their personality and study performance. Due to these differences, there is an intense need to develop a scale of academic stress for students that would be able to depict the real picture of the stress of Pakistani University students and would cover all the domains and aspects of their stress in indigenous culture. The current study was intended to attain the following objectives:

1. To develop an indigenous scale of academic stress in Urdu for university students of Pakistan.

2. For determining the psychometric properties of existing scale.

3. To determine gender differences in academic stress.

4. To investigate the relationship of Academic Stress Scale with Loneliness, Depression and Fear of Negative Evaluation Scale.

Three independent studies were conducted to achieve the abovementioned objectives.

\section{Study I: Construction of Academic Stress Scale for University Students}

\section{Item Pool Generation}

Semi-structured interviews were conducted with the students to generate item pool. Literature review, expert opinion and already developed Academic Stress scales were also consulted to generate the items for Academic Stress Scale for University Students. Initially 62 items were generated. Items scrutiny was carried out through a committee of teachers including two lecturers and one assistant professor from Psychology department, University of Sargodha, Pakistan. Ten out of 62 items were rephrased. Accurate, non-repeated and clear items were selected having conformity with the construct. At the end selected items were written in scale form. Five-point Likert response format was used for Academic Stress Scale for University Students, ranged from 1= strongly disagree to 5= strongly agree because it captures the variation that points to the underlying phenomena. Participants revealed their level of agreement or disagreement for a series of statements. Intensity of feelings for a given statement was measured through this format (Burn \& Alvin, 2008; Burns \& Ronald, 2008). 


\section{Pilot Study}

Initial Psychometric properties of Academic Stress scale were determined through pilot study. Overlapping, ambiguous and unclear statements were excluded and accuracy and understandability of the items in scale was maintained. A sample of 100 students of BS, MSc and M.Phil, age range between $18-28(M=19.14, S D=1.39)$ was taken for pilot study from University of Sargodha.

\section{Results}

Through pilot study viability of items in Academic Stress Scale for University Students and final number of items for factor analysis were selected. Significant positive correlation was found between items. Feedback was taken from the participants if they find any problematic item that was ambiguous or unclear. Ten items were excluded through pilot study.

\section{Factor Structure and Internal Consistency of Academic Stress Scale for University Students}

\section{Sample}

A purposive sample consisting of $(N=477)$ students was taken from University of Sargodha. Purposive sample is logically assumed to be representative of the population. Sample consisted of boys $(n=226)$ and girls $(n=251)$ between age range of 18-28 $(M=18.10, S D=1.19)$ years. Students of BS, MSc and M.Phil were taken from social sciences, pure sciences and arts departments.

\section{Procedure}

Academic Stress Scale for University Students (ASS) was administered on 500 students of University of Sargodha.477 out of 500 (95.4\%) forms was returned back. Participants were approached in their classes. After taking informed consent instructions were provided them to fill the questionnaires. They were requested to fill the questionnaires with full concentration and not to skip any question. They were ensured about confidentiality of given information. They were also guaranteed that provided data will be used only for research purpose. After data collection they were thanked for their cooperation. 23 forms were found to be incomplete and were not included in the data of current study. 


\section{Results}

SPSS version 20 was used to carry the exploratory factor analysis to ensure the construct validity and dimensionality of newly developed academic stress scale. Direct Oblimin rotation method was applied on the data of 477 individuals. Three factors were obtained by EFA with eigen value > 1.0. An appropriate structure with three well defined and interpretable factors was obtained. Retained factors accounted a significant amount of variance of $36 \%$ (Table 1).

Table 1

Factor loading of 26 items on Academic Stress Scale for University Students $(N=477)$

\begin{tabular}{|c|c|c|c|c|}
\hline \multicolumn{5}{|c|}{ Factors } \\
\hline & & 1 & II & III \\
\hline New nos. & No. of items & PPTA & PWE & CESM \\
\hline 1 & 31 & .49 & .29 & .22 \\
\hline 2 & 32 & .47 & .29 & .16 \\
\hline 3 & 35 & .48 & .22 & .35 \\
\hline 4 & 39 & .55 & .18 & .15 \\
\hline 5 & 55 & .58 & .25 & .16 \\
\hline 6 & 58 & .65 & .22 & .16 \\
\hline 7 & 59 & .62 & .14 & .29 \\
\hline 8 & 60 & .58 & .24 & .04 \\
\hline 9 & 61 & .65 & .22 & .11 \\
\hline 10 & 7 & .17 & .51 & .29 \\
\hline 11 & 10 & .30 & .57 & .20 \\
\hline 12 & 11 & .30 & .60 & .16 \\
\hline 13 & 12 & .20 & .61 & .28 \\
\hline 14 & 13 & .14 & .58 & .30 \\
\hline 15 & 15 & .27 & .56 & .25 \\
\hline 16 & 16 & .17 & .63 & .20 \\
\hline 17 & 18 & .22 & .60 & .26 \\
\hline 18 & 19 & .30 & .57 & .04 \\
\hline 19 & 5 & .24 & .28 & .55 \\
\hline 20 & 6 & -.02 & .20 & .52 \\
\hline 21 & 27 & .09 & .19 & .66 \\
\hline 22 & 28 & .15 & .21 & .66 \\
\hline 23 & 29 & .25 & .16 & .63 \\
\hline 24 & 30 & .28 & .21 & .56 \\
\hline 25 & 46 & .31 & .22 & .50 \\
\hline 26 & 47 & .33 & .13 & .49 \\
\hline Eigen values & & 5.55 & 2.03 & 1.77 \\
\hline$\%$ of variance explained & & 21.34 & 7.83 & 6.82 \\
\hline Cumulative variance & & 21.34 & 29.17 & 36.0 \\
\hline
\end{tabular}


Three clear and well-defined factors were obtained as a result of principal axis factoring with direct oblimin rotation method. All items were loaded independently on three factors. Loadings for all items were greater than .3 (Coakes \& Steed, 2003) that confirmed appropriateness of correlation matrix. The obtained factor structure indicated that all the three factors were theoretically and conceptually distinct from each other.

Factor-I Personal, Parental and Teachers' attitude. Nine items $(16,17,18,19,22,23,24,25,26$ (e.g.i. Our teachers' attitude is biased ii. Parental disputes are source of mental distress for me) were independently loaded on factor I and represent personal, parental and teacher's concerns. So, this factor was named as personal, parental and teacher's attitude.

Factor-II Perception of Workload and Examinations. On factor II nine items (3, 4, 5, 6, 7, 8, 9, 10,11( e.g i. Exams in semester system are source of stress for me ii. Day by day increasing educational competition is frustrating me) were independently loaded. Workload of assignments, presentations, quiz, projects, seminars, tests, exams etc were reflected by all items, hereafter the factor was named as perception of workload and examinations.

Factor-III Concerns about Education system and Management. Eight items $(1,2,12,13,14,15,20,21$ (i. Proper guidance is not provided by university administration ii. Insufficient practical work is an obstacle in my educational performance) were independently loaded on factor III. Retained items were representing issues related to education system and management, therefore named as concerns about education system and management.

Table 2

Mean, Standard Deviation, Alpha Reliabilities and Correlation Matrix Academic Stress Scale for University Students and its Subscales (N=477)

\begin{tabular}{ccccccccc}
\hline & Variables & $M$ & $S D$ & $\alpha$ & $\mathrm{F} 1$ & $\mathrm{~F} 2$ & $\mathrm{~F} 3$ & $\begin{array}{c}\text { Full } \\
\text { Scale }\end{array}$ \\
\hline 1 & Factor 1 & 28.56 & 7.38 & .75 & -- & $.46^{* *}$ & $.38^{* *}$ & $.81^{* *}$ \\
2 & Factor 2 & 27.7 & 6.72 & .76 & & -- & $.41^{* *}$ & $.80^{* *}$ \\
3 & Factor 3 & 26.87 & 5.95 & .72 & & & -- & $.73^{\star *}$ \\
4 & Full scale & 83.15 & 15.75 & .85 & & & & -- \\
\hline$* * p<0.01$ & & & & & & &
\end{tabular}

Table 2 shows that coefficients of reliability ranges from .72 (concerns about education system and management) to .76 (personal, parental and teachers' attitude). Coefficients indicate that a high internal consistency. The full scale indicates excellent alpha reliability $(\alpha=.85)$. 
Table 3

Mean, Standard Deviation, Significance level and t-values of Male and Female on Total and Subscales of Academic Stress Scale for University Students $(N=477)$

\begin{tabular}{lcccccccc}
\hline & $\begin{array}{c}\text { Males } \\
(n=226)\end{array}$ & \multicolumn{3}{c}{$\begin{array}{c}\text { Females } \\
(n=251)\end{array}$} & & & & \multicolumn{2}{c}{$95 \% \mathrm{Cl}$} \\
\hline Variables & $M$ & $S D$ & $M$ & $S D$ & $T$ & $L L$ & UL & Cohen's d \\
\hline ASS & 83.37 & 16.12 & 82.95 & 15.44 & .290 & -2.42 & 3.26 & 0.02 \\
PPTA & 29.12 & 7.97 & 28.06 & 6.79 & 1.56 & -.272 & 2.38 & 0.14 \\
PWE & 27.05 & 6.82 & 28.29 & 6.58 & $2.00^{*}$ & -2.44 & - & 0.18 \\
& & & & & & & 0.26 & \\
CESM & 27.19 & 5.7 & 26.59 & 6.12 & 1.09 & -.475 & 1.66 & 0.10 \\
\hline
\end{tabular}

Note: $M=$ mean; $S D=$ standard deviation; $P P T A=$ Personal, Parental and Teachers Attitude; $P W E=$ Perception of Workload and Examinations; $C E S M=$ Concerns about Education System and Management; ASS= Academic Stress Scale for University Students ${ }^{*} p<0.05$

Table 3 shows differences of males and females on Academic Stress Scale for University students and its subscales. The $t$ value indicates significant gender differences on Perception of Workload and Examination $(t(477)=2.00, p<.05)$. Mean and standard deviation indicate females have higher score $(M=28.29, S D=6.58)$ than males $(M=27.05$, $S D=6.82$ ). Results show non-significant gender differences in Personal, Parental and Teachers Attitude and Concerns about Education System and Management and Academic Stress Scale for University students

\section{Study II Confirmatory Factor Analysis CFA}

\section{Sample}

Purposive sample of study was consisted of students ( $N=200)$. Equal representation was given to males $(n=100)$ and female $(n=100)$ with age range of 18-28 $(M=20.02, S D=1.30)$.

\section{Procedure}

With the permission of heads of departments of concerned departments participants of study were approached in their classrooms. They were directed about the purpose of present study. After taking informed consent questionnaires were dispersed among willing participants. It took about 25-30 minutes to complete the questionnaires. 
Participants showed high cooperation during data collection. They were acknowledged for their support and cooperation.

\section{Results}

To ensure the factor structure of newly developed Academic Stress Scale for University Students confirmatory factor analysis was performed on independent sample of students by using SPSS 20 version. Different indices and criteria were checked containing (GFI, CFI, TLI and RMSEA) for explaining best model fit. Obtained model was confirmed through confirmatory factor analysis. A good fit to data was showed by three factor structure with chi square $570.4(d f=288), \mathrm{CFI}=.90, \mathrm{RMSEA}=.04$ and GFI=.91. Finally obtained model was consisted of three well defined domains having 9 items in personal, parental and teachers' attitude, 9 items in perception of workload and examinations and 8 items in concerns about education system and management. Factor loadings ranged from .47 to .66. Alternative two factor, single factor and four factors were also tried but model appeared fit with only three factor structure.

Table 4

Model Fit Indices of CFA for Academic Stress Scale for University Students $(N=350)$

\begin{tabular}{lccccccc}
\hline Indexes & Chi square & $d f$ & Chi square/df & CFI & RMSEA & GFI & TLI \\
\hline Model & 570.47 & 288 & 1.98 & .90 & .04 & .91 & .90 \\
\hline
\end{tabular}




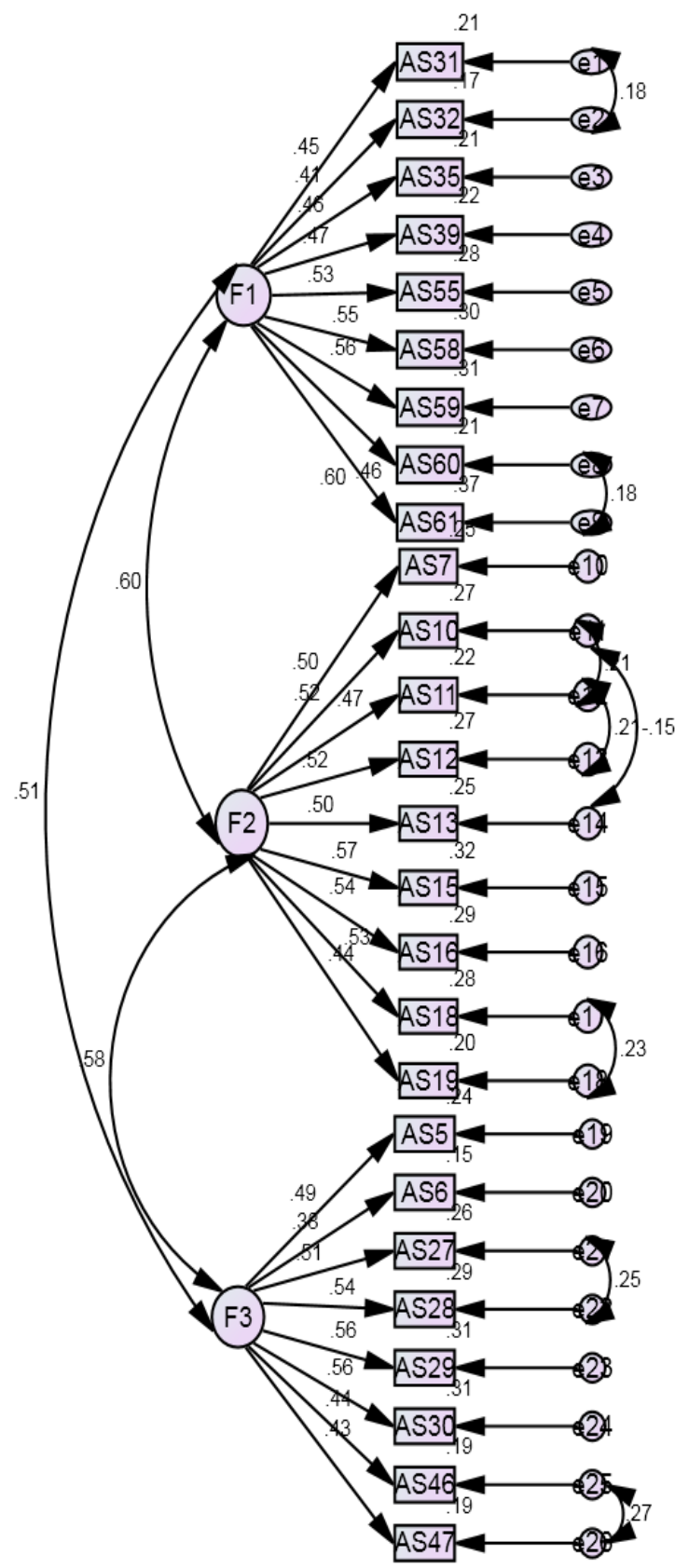

Figure 1. Measurement model of Academic Stress Scale for University Students 


\section{Study III: Validation of Academic Stress Scale for University Students}

\section{Sample}

A sample of 120 students including males and females in age range of 18-28 $(M=23.14, S D=1.39)$ years was taken from University of Sargodha. Students of BS, MSc and M.Phil. were recruited to collect data. Purposive sampling technique was used for collection of data.

\section{Instruments}

Newly developed Academic Stress Scale (ASS), Depression (DASS), Revised UCLA scale of Loneliness, and Brief Fear of Negative Evaluation scale (BFNE).

Academic Stress Scale for University Students. In Study III the complete description of existing scale (ASS- 26) is provided (see Annexure B-4). This instrument has three domains; named as personal, parental and teachers attitude including 9 items, perception of workload and examinations containing 9 items and concerns about education system and management including 8 items. Five-point Likert response format was used ranging from $(1=$ strongly disagree to $5=$ strongly agree). Alpha reliability for Academic Stress Scale for University Students of Pakistan was found to be .85 .

Depression Subscale of DASS-21 (Farooqi \& Habib, 2010). This scale was developed by Lovibond and Lovibond (1995). Farooqi and Habib (2010) translated it in Urdu language. In present study items related to stress were used only in finding convergent validity of present stress scale. Only depression subscale of DASS-21 was used in current research. This domain comprised of 7 items including 3,5,10,13,16,17,21 with response format of four-point rating scale ranged from $(0=$ did not apply to me at all to $3=$ applied to very much, most of the time). Internal consistency of original scale of DASS subscales ranging from .91 to .97 , while internal consistency of translated versions ranges from 0.94 to 0.97 .

Revised UCLA Loneliness Scale (Anjum \&Batool, 2016). The UCLA the scale of loneliness was constructed to measure the feelings of social isolation and loneliness among people. Items were based on statements taken by lonely individuals for description of loneliness in original version of this scale. The response format was four- point rating 
scale ranging from $(1=$ not at all to $4=$ often). Original UCLA Loneliness Scale comprised of 20 statements. All the questions in this version were in negative direction. In revised version ten items phrased in negative direction and ten items were phrased in positive direction. Moreover 10 statements in this version deal with satisfaction of a person with social relationships and 10 statements deal with dissatisfaction. Items 1, 4, 5, 6, $9,10,15,16,19$ and 20 are reverse scored items. Reliability of this scale was 0.94 .

Brief Fear of Negative Evaluation Scale (Leary, 1983). The instrument was constructed by Leary (1983). It measures the level of apprehension of being negatively evaluated by others. It is a brief version of 30 item scale with true/false format. It has five point likert type response format in range between ( $1=$ not at all characteristics of me to $5=$ extremely characteristics of me). 8 items in scale are straight forward while remaining 4 items $(2,7,10,11)$ are reversely scored items. High scorers on this scale were found to be worse in receiving negative feedback. The internal consistency of scale was 0.90 and test retest reliability coefficient was .75.

\section{Procedure}

All the measures including newly developed scale of Academic Stress Scale for University Students (ASS) were administered on 120 students of University of Sargodha. Participants were approached in their classes. After taking informed consent instructions were provided them to fill the questionnaires. They were requested to fill the questionnaires with full concentration and not to skip any question. They were ensured regarding to confidentiality of provided data and use of this data only for research purpose. After data collection they were thanked for their cooperation.

\section{Results}

Table 5

Correlation of Total Academic Stress Scale for University Students with Loneliness, Depression and Fear of Negative Evaluation $(N=151)$

\begin{tabular}{lcccc}
\hline & ASS & LON & DEP & FNE \\
\hline ASS & - & $.20^{*}$ & $.16^{*}$ & $.17^{*}$ \\
LON & & - & $.42^{* *}$ & $.41^{* *}$ \\
DEP & & & - & $.53^{* *}$ \\
FNE & & & & - \\
\hline$* p<.01, *^{*} p<.05$ & & & &
\end{tabular}


Table 5 indicates that Academic stress scale for university students has a significant positive correlation with loneliness $(r=.20, p<.05)$, Depression $(r=.16, p<.05)$ and Brief fear of negative evaluation $(r=.17$, $p<.05)$. Loneliness has significant positive correlation with Depression $(r=.42, p<.01)$ and Brief fear of negative evaluation $(r=.41, p<.01)$. Depression indicates significant positive correlation with Brief fear of negative evaluation scale $(r=.53, p<.01)$.

\section{Discussion}

Current study was aimed to construct an indigenous scale to measure level of academic stress among university students. Exploratory factor analysis revealed three well defined and distinct factors with 26 retained items named as personal, parental and teachers' attitude, perception of workload and examination and concerns about education system and management.

Factor I contain 9 items related to personal, parental and teacher's attitude that are source of stress for students. Personal characteristics of students like, lack of interest, being emotional, lack of self-perception, shyness and lack of internal motivation hinders the success of students (Bernstein, Penner, Clarke-Stewar \& Roy, 2008). Strict parents do not allow children to share their feelings and problems with them (Grolnick, 2003). Their unrealistic expectations are frightening for students. Similarly, strict teachers who do not allow the students to express themselves, do favor of some students and do not teach according to mental capacity of students are source of stress for them (Rehman \& Khan, 2011).

Factor II contains 9 items related to workload and examination system. Workload of assignments, presentations, quiz, projects, seminars, tests and exams and too little time for these tasks is source of stress for students because managing all these tasks in short time is difficult for them (Both et al, 2009).

Factor III consists of 8 items related to concerns about education system and management. Weaknesses in education system of Pakistan including expensive and difficult education, rote learning, lack of facilities etc are sources of stress for our students (Rehman \& Khan, 2011). Non cooperative attitude of university and department administration delays the important matters of students that create frustration and stress among them and effect their studies as well (Burge, 2009).

Perception of academic stress is different for students of different cultures due to variations in social, cultural and religious backgrounds. 
Being in collectivistic culture our students are strongly bonded with their parents. Conflicts among their relationship is source of stress for students. Attitude of parents can make their children active and encouraging as well as negative and feeble. According to Jeynes (2005) parental involvement enhances the chances of success for students. There are rare quality teachers in Pakistani institutes (Rehman \& Khan, 2011). Sudden medium change at university level is cause of stress for students (Marsh, Hau and Kong, 2006). Flaws in Pakistani education system including political interference hinders the success of our students. Reflection, critical thinking and analytical skills of students are negated due to rote learning (Rehman \& Khan, 2011).

Results of this study revealed that gender have noteworthy mean effect on academic stress. Females showed higher level of stress on perception of workload and examination subscale than males as they are emotionally weak as compare to males (see Table 3). They become worried easily. Perception of stress and coping strategies towards stress are different for females than males. Females are more sensitive and when playing different roles with reference to men in their lives it's difficult for them to manage their study related problems. The results are consistent with previous body of knowledge (Matud, 2004). Males as well as females both have non-significant differences for personal, parental and teachers' attitude and concerns about education system and management subscales and total ASS.

The study was also aimed to find the convergent validity of newly constructed academic stress scale for university students. Associations between academic stress scale, loneliness, depression and brief fear of negative evaluation was calculated. Convergent validity of academic stress scale was confirmed by findings. Academic stress among students was found to be significantly positively correlated with depression, loneliness and fear of negative evaluation (see Table 5).

These indications were a replication of the results obtained by previous researches that academic stress is cause of fear of negative evaluation among students (Fay et al., 2008).Other findings also reported that academic stress causes academic failure that is positively correlated with depression (Esia-Donkoh et al., 2011).According to Chenet., al (2009) depressed feelings are developed among students who experience academic difficulties and receive negative feedback. Tosevski, Milovancevic, and Gajic (2010) concluded that different kinds of psychological problems faced by stressed students including impaired self-concept, destructive behavior, loneliness, anxiety and depression that decline their performance and negatively affect their health. According to 
Ongori (2007) academic stress is cause of pathological symptom among university students.

\section{Limitations, Suggestions and Practical Implications}

The following study has various limitations that are subject to be addressed in future studies. Full representation of Pakistani students from whole country might be doubtful as the data was collected only from University of Sargodha Pakistan. To get a broad and clear picture students from different universities, departments, classes, religions and races should be the part of upcoming studies.

\section{Practical Implications}

The present study has various practical implications. The newly developed scale of academic stress will help the parents, teachers and educationalists to know how academic stress effects our students. It will help the parents and teachers to change their attitude that will be helpful in enhancing the performance of students. It will play important role in developing appropriate tactics for betterment of study quality of students in Pakistan. Results of study will also help the educational psychologists to facilitate the students to achieve their goals.

\section{Acknowledgements}

Dr. Adnan Adil provided support in the whole research work. 


\section{References}

Abouserie, R. (1994). Sources and level of stress in relation to locus of control and self-esteem in university students. Educational Psychology, 14(3), 323-330. doi.org/10.1080/0144341940140306

Agolla, J. E. (2009). Occupational stress among police officers: the case of Botswana police service. Research Journal of Business Management, 2(1), 25-35. doi.10.3932/ribm.2009.23.35

Ahmed, K.A., Sharif, N., \& Ahmad, N. (2017). Factors influencing students career choices: empiriscal evidence from business students. Journal of Southeast Asian Research, 1-15. doi. 10.5171/2017.718849

Anjum, W., \& Batool, I. (2016). Translation and cross language validation of Passionate Love Scale among adults in Lahore, Pakistan. doi.org/10.23668/psycharchives.2129

Argon, T. (2009). The development and implementation of a scale to assess the causes of conflict in the classroom for university students. Educational Sciences: Theory and Practice, 9(3), 1033-1041.

Awino, J. O., \& Agolla, J. E. (2008). A quest for sustainable quality assurance measurement for universities: Case study of the University of Botswana. Educational Research and Reviews, 3(6), 213. doi.org/10.5897/ERR.9000009

Balamurugan, M., \& Kumaran, D. (2008). Development and validation of Students' Stress Rating Scale (SSRS). Online Submission, 7(1), 35-42.

Bedewy, D., \& Gabriel, A. (2013). The Development and psychometric assessment of a scale to measure the severity of examination anxiety among undergraduate university students. International Journal of Educational Psychology, 2(1), 81-104.

Bernstein, D. A., Penner, L. A., Stewart, A.C., \& Roy, E.J. (2008). Psychology ( $8^{\text {th }}$ edition). Houghton Mifflin Company Boston New York.

Bisht, A.R. (1998). Bisht Battery of Stress Scales. Agra: National Psychological Corporation.

Blona, R. (2005). Coping with stress in a changing world. New York: The McGraw Hills Companies. 
Both, F., Hoogendoorn, M., Lambalgen, R. V., Oorburg, R., \&Vos, M. D. (2009). Relating personality and physiological measurements to task performance quality. In Proc. of the 31st Annual Conference of the Cognitive Science Society, CogSci (pp. 2819-2825).

Boujut, E., \& Bruchon-Schweitzer, M. (2009). A construction and validation of a freshman stress questionnaire: An exploratory study. Psychological Reports, 104(2), 680-692. doi.org/10.2466/pr0.104.2.680-692

Burge, J. (2009). Coping frequency, coping effectiveness and personality factors in university students. Unpublished Honours thesis, University of Canberra, Australia.

Burns, Alvin, C. (2008). Basic Marketing Research. Pearson Education.

Chacón-Cuberos, R., Zurita-Ortega, F., Olmedo-Moreno, E. M., \& CastroSánchez, M. (2019). Relationship between academic stress, physical activity and diet in university students of education. Behavioral Sciences, 9(6), 59. doi:10.3390/bs9060059

Chang, K., \& Lu, L. (2007). Characteristics of organizational culture, stressors and wellbeing: The case of Taiwanese organizations. Journal of Managerial Psychology, 22(6), 549-568. doi.org/10.1108/02683940710778431

Chen, H., Wong, Y. C., Ran, M. S., \& Gilson, C. (2009). Stress among Shanghai university students: The need for social work support. Journal of Social Work, 9(3), 323-344. doi.org/10.1177/1468017309334845

Coakes, S.J., \& Steed, L.G. (2003) Analysis without anguish using SPSS version 11.0 for windows. Milton, Queensland: John Wiley \& Sons.

Cohen, S., Kamarck, T., \& Mermelstein, R. (1983). A global measure of perceived stress. Journal of Health and Social Behavior, 24, 385-396. doi. $10.2307 / 2136404$

Cooley, E., Toray, T., Valdez, N., \& Tee, M. (2007). Risk factors for maladaptive eating patterns in college women. Eating and Weight Disorders-Anorexia, Bulimia and Obesity, 12(3), 132-139. doi.org/10.1007/BF03327640

Dyck, D., \& Roithmayr, T. (2001). The toxic workplace. Benefits Canada, 25(3), 52-52. doi.org/10.22215/etd/2017-11743

Ellison, K. W. (2004). Stress and the police officer. Charles C Thomas Publisher. 
Erkutlu, H. V., \& Chafra, J. (2006). Relationship between leadership power bases and job stress of subordinates: example from boutique hotels. Management Research News, 29(5), 285-297. doi.org/10.1108/01409170610674419

Esia-Donkoh, K., Yelkpieri, D., \& Esia-Donkoh, K. (2011). Coping with stress: Strategies adopting by students at the Winneba campus of university of education, Winneba, Ghana. US-China Education Review B, 2, 290-299.

Fairbrother, K., \& Warn, J. (2003). Workplace dimensions, stress and job satisfaction. Journal of Managerial Psychology, 18(1), 8-21. doi.org/10.1108/02683940310459565

Farias, S. M. D. C., Teixeira, O. L. D. C., Moreira, W., Oliveira, M. A. F. D., \& Pereira, M. O. (2011). Characterization of the physical symptoms of stress in the emergency health care team. Revista da Escola de Enfermagem da USP, 45(3), 722-729. doi. 10.1590/S0080-62342011000300025

Farooqi, Y., \& Habib, M. (2010). Gender differences in anxiety, depression, and stress among survivors of suicide bombing. Pakistan Journal of Social and Clinical Psychology, 8(2), 145-153.

Feldt, R. C. (2008). Development of a brief measure of college stress: The college student stress scale. Psychological reports, 102(3), 855-860. doi.org/10.2466/pr0.102.3.855-860

Furnham, S. (2004). Foreign students: Education and culture shock.

Gajalakshmi, G., Kavitha, U., Anandarajan, B., \& Chandrasekar, M. (2012). A study to analyze various factors contributing to stress in first year MBBS students during examination. International Journal of Biomedical and Advance Research, 3(9), 700-703.

Gelow, Z.A., Brown, J.B., Dowling, W.A., \& Torres, P.D. (2009). Stress, general health and academic performance. In Ninth annual AIBER and TLC conference proceedings. Las Vegas:NV, USA.

Grolnick, W. S. (2003). The psychology of psychological control: How well-meant parenting backfires.

Iyamu, E. O., \& Obiunu, J. J. (2006). The Dilemma of Primary School Attendance in Nigeria. Journal of Instructional Psychology, 33(2).

Jackson, C. (2010). Fear in education. Educational Review, 62, 39-52. doi.org/10.1057/9781137269 
Jeynes, W. H. (2005). A meta-analysis of the relation of parental involvement to urban elementary school student academic achievement. Urban Education, 40(3), 237-269. doi.org/10.1177/0042085905274540

Kalaithasan A, Tye SC, Fatimatuzzahra' AA, et al. Prevalence, factors associated and coping strategies of stress among pharmacy students in a public university in Malaysia. Pharm Pharmacol Int $J$. 2020;8(2):64-71. Doi. 10.15406/ppij.2020.08.00281

Kaplin, H.I., \&Sadock, B.J. (2000). Learning theory: Synopsis of Psychiatry: Behavioral sciences/Clinical psychology.

Klainin-Yobas, P., Keawkerd, O., Pumpuang, W., Thunyadee, C., Thanoi, W., \& He, H.G. (2014). The mediating effects of coping on the stress and health relationships among nursing students: a structural equation modeling approach. Journal of Advanced Nursing,70(6),1287-1298. doi.org/10.1111/jan.12283

Leary, M. R. (1983). A brief version of the Fear of Negative Evaluation Scale. Personality and Social Psychology Bulletin, 9(3), 371-375. doi.org/10.1177/0146167283093007

Lovibond, S.H. \& Lovibond, P.F. (1995). Manual for the Depression Anxiety Stress Scales. (2 ${ }^{\text {nd }}$. Ed.) Sydney: Psychology Foundation. ISBN 7334-1423-0.

Malik, P.R. \&Balda, S. (2006). High IQ adolescents under stress: Do they perform poor in academics. The Anthropologist, 8(1),61-62. doi.org/10.1080/09720073.2006.11890937

Marsh, H. W, Hau, K. T \& Kong, C. K. (2006). Multilevel causal ordering of academic self-concept and achievement: Influence of language, of instruction (English Compared with Chinese) for Hong Kong Students. American Educational Research Journal, 39(3) 727-763. doi.org/10.3102/00028312039003727

Matud, M. P. (2004). Gender differences in stress and coping styles. Personality and Individual Differences, 37(7), 1401-1415. doi.org/10.1016/j.paid.2004.01.010

Mori, S. C. (2000). Addressing the mental health concerns of international students. Journal of Counseling \& Development, 78(2), 137-144. doi.org/10.1002/j.1556-6676.2000.tb02571.x 
Murphy, M.C., \& Archer, J. (1996). Stressor on the college campus: A comparison of 1985-1993. Journal of College Student Development.9(1), 22-25.

Novotney, A. (2010). Procrastination or intentional delay. American Psychological Association, 14(10), 45-49.

Oberg, K. (1960). Cultural shock: Adjustment to new cultural environments. Practical Anthropology, 7(4), 177-182. doi.org/10.1177/009182966000700405

Ongori, H. (2007). A review of the literature on employee turnover. African Journal of Business Management, 4. 049-054

Ramli, N. H., Alavi, M., Mehrinezhad, S. A., \& Ahmadi, A. (2018). Academic stress and self-regulation among university students in Malaysia: Mediator role of mindfulness. Behavioral Sciences, 8(1), 12. doi. $10.3390 / \mathrm{bs} 8010012$

Reddy, K. J., Menon, K. R., \& Thattil, A. (2018). Academic stress and its sources among University students. Biomedical and Pharmacology Journal, 11(1), 531-537. doi.org/10.13005/bpj/1404

Rees, C. J., \& Redfern, D. (2000). Recognising the perceived causes of stress-a training and development perspective. Industrial and Commercial Training, 32(4), 120-127. doi.org/10.1108/00197850010372197

Rehman, H., \& Khan, N. (2011). Flaws in Pakistan's Educational System. Abasyn University Journal of Social Sciences, 4(1). 2-20

Reynolds, J.R., Michael. S., Ryan M. \& Lacey S (2006). "Have Adolescents Become Too Ambitious? High School Seniors' Educational and Occupational Plans 1976 to 2000." doi.org/10.1525/sp.2006.53.2.186

Shaikh, B. T., Kahloon, A., Kazmi, M., Khalid, H., Nawaz, K., Khan, N., \& Khan, S. (2004). Students, stress and coping strategies: a case of Pakistani medical school. Education for Health-Abingdon -Carfax Publishing Limited-, 17, 346-353. doi.10.1080/13576280400002585

Smith, A. (2000). The scale of perceived occupational stress. Occupational Medicine, 50(5), 294-298.Social Problems, 53(2),186206. doi.org/10.1093/occmed/50.5.294 
Stallman, H. M., \& Hurst, C. P. (2016). The University Stress Scale: Measuring Domains and Extent of Stress in University Students. Australian Psychologist, 51(2), 128-134. doi.org/10.1111/ap.12127

Stevenson, A., \& Harper, S. (2006). Workplace stress and the student learning experience. Quality Assurance in Education, 14(2), 167-178. doi.org/10.1108/09684880610662042

Sun, J., Dunne, M. P., Hou, X. Y., \& Xu, A. Q. (2011). Educational stress scale for adolescents: development, validity, and reliability with Chinese students. Journal of Psychoeducational Assessment, 29(6), 534-546. doi.org/10.1177/0734282910394976

Sung, Y. T., \& Chao, T. Y. (2015). Construction of the examination stress scale for adolescent students. Measurement and Evaluation in Counseling and Development, 48(1), 44-58. doi.org/10.1177/0748175614538062

Tosevski, D. L., Milovancevic, M. P., \&Gajic, S. D. (2010). Personality and psychopathology of university students. Current opinion in psychiatry, 23(1), 48-52. doi: 10.1097/YCO.0b013e328333d625

Tweedet, R. G., White, K., \& Lehman, D. R. (2004). Culture, stress, and coping: Internally and externally targeted control strategies of European Canadians, East Asian Canadians, and Japanese. Journal of Cross-Cultural Psychology, 35(6), 652-668. doi.org/10.1177/0022022104270109

Ward, C. A., Bochner, S., \& Furnham, A. (2001). The psychology of culture shock. Psychology Press.

Ward, C., \&Rana-Deuba, A. (1999). Acculturation and adaptation revisited. Journal of cross-cultural psychology, 30(4), $422-442$. doi.org/10.1177/0022022199030004003

Worku, D., Dirriba, A. B., Wordofa, B., \& Getahun, F. (2020). Perceived Stress, Depression, and Associated Factors among Undergraduate Health Science Students at Arsi University in 2019 in Oromia, Ethiopia. Psychiatry Journal, 2020. doi.org/10.1155/2020/4956234

Yeh, C. J., \& Inose, M. (2003). International students reported English fluency, social support satisfaction, and social connectedness as predictors of acculturative stress. Counselling Psychology Quarterly, 16(1), 15-28. doi.org/10.1080/0951507031000114058. 
Citation of this Article:

Noreen, S., Ghayas, S., Khalid, S., \& Awan, S. M. (2021). Construction and validation of academic stress scale for university students. Pakistan Journal of Education, 38(2), 1-24. 